\title{
A SEGURANÇA ALIMENTAR NAS RELAÇÕES DE CONSUMO: POLÍTICAS PÚBLICAS PARA A CONCRETIZAÇÃO DO DIREITO FUNDAMENTAL SOCIAL À ALIMENTAÇÃO
}

\section{FOOD SECURITY IN CONSUMER RELATIONS: PUBLIC POLICIES FOR THE CONCERTATION OF FUNDAMENTAL SOCIAL FOOD LAW}

Danilo Henrique Nunes Lucas de Souza Lehfeld

Data e Recebimento: 14/02/2018

Data de Aprovação: 10/08/2018

\section{RESUMO}

Uma das grandes preocupações relacionadas à dignidade da pessoa humana em âmbito global consiste na alimentação dos indivíduos, aspecto considerado indispensável para o seu desenvolvimento, bem-estar, qualidade de vida, manutenção da saúde e da própria vida. O presente estudo busca analisar as políticas públicas de segurança alimentar nas relações de consumo como condição indispensável para a promoção do direito fundamental social à alimentação e concreção da cidadania, que é também condição para uma vida

Danilo Henrique Nunes, DHN; Mestre em Direitos Coletivos e Cidadania pela Universidade de Ribeirão Preto - Unaerp, curso com conceito 4 no CAPES/MEC e professor universitário do Centro Universitário Estácio de Ribeirão Preto/SP e do Centro Universitário da Fundação Educacional de Barretos/SP. Advogado.

Lucas de Souza Lehfeld, LSH; Professor-doutor orientador do Programa de Mestrado em Direitos Coletivos e Cidadania na Universidade de Ribeirão Preto - Unaerp, curso com conceito 4 no CAPES/MEC. Advogado. 
saudável e digna. Respaldada em autores que já analisaram essa temática, o estudo consiste em uma abordagem da questão alimentar com base nos preceitos jurídicos e sociais, buscando analisar os parâmetros atuais envolvendo a Segurança Alimentar e o Direito Humano à Alimentação Adequada, bem como as ações realizadas pelo Estado com o intuito de efetivar tais direitos. A pesquisa orientou-se pelo método dedutivo, com fulcro em livros, artigos científicos e publicações especializadas, resultando, por fim, na necessidade imperiosa do desenvolvimento e aperfeiçoamento de políticas públicas de segurança alimentar com vistas à concreção de direitos de cidadania.

\section{PALAVRAS-CHAVE}

Segurança Alimentar; Relações de Consumo; Direito Humano à Alimentação Adequada; Políticas Públicas. Cidadania.

\section{ABSTRACT}

One of the major concerns related to the dignity of the human person at a global level is the feeding of individuals, an aspect considered indispensable for their development, well-being, quality of life, maintenance of health and life itself. The present study seeks to analyze public policies on food safety in consumer relations as an indispensable condition for the promotion of the fundamental social right to food and concretion of citizenship, which is also a condition for a healthy and dignified life. Backed by authors who have already analyzed this theme, the study consists of an approach to the food question based on legal and social precepts, seeking to analyze the current parameters involving Food Security and the Human Right to Adequate Food, as well as the actions carried out by the State with the purpose of effecting such rights. The research was guided by the deductive method, with a focus on books, scientific articles and specialized publications, resulting, finally, in the imperative need to develop and improve public food security policies with a view to realizing citizenship rights.

\section{KEYWORDS}

Food Security; Consumer Relations; Human Right to Adequate Food; Public policy. Citizenship. 


\section{INTRODUÇÃO}

Os Direitos Humanos são amplamente valorizados na contemporaneidade, visto que os mesmos são contemplados pela perspectiva de oferecimento das condições básicas de vida a todos os seres humanos, com base no princípio da dignidade da pessoa humana. Dentro dos Direitos Humanos, encontramse o direito à vida, liberdade, saúde, educação, moradia e, evidentemente, um direito amplamente relacionado à qualidade de vida e ao bem-estar, bem como à própria saúde e segurança do indivíduo humano: $\mathrm{O}$ direito à alimentação.

A alimentação é uma atividade indispensável para a sobrevivência do ser humano, sendo responsável pelo desenvolvimento do indivíduo. Dentro desse contexto, além de ser considerada um direito humano, a alimentação é considerada um direito fundamental social. Todavia, não basta que os indivíduos tenham acesso aos alimentos, mas também que os alimentos sejam adequados para a manutenção da vida humana.

A partir de tais entendimentos, são fundamentadas perspectivas envolvendo a Segurança Alimentar e o Direito Humano à Alimentação Adequada (DHAA), preceitos de ampla preocupação internacional no âmbito alimentar, social e jurídico para toda a humanidade. Conforme apontado na Política Nacional de Segurança Alimentar brasileira, todos os indivíduos que vivem no território nacional devem ser beneficiados pelos esforços públicos realizados no sentido de assegurar uma alimentação de qualidade.

O presente estudo busca analisar a Segurança Alimentar e o Direito Humano à Alimentação Adequada dentro de diferentes contextos, sendo que o principal contexto diz respeito à segurança alimentar nas relações de consumo, sobretudo diante dos elementos dispostos no Código de Defesa do Consumidor (CDC) nas relações de consumo. Ademais, destacam-se ainda outras políticas públicas concentradas no âmbito do oferecimento da segurança alimentar e do acesso ao direito de alimentação adequada a todos os indivíduos, como os programas que buscam o oferecimento de alimentos adequados para os indivíduos, bem como a Política Nacional de Segurança Alimentar como um todo. 


\section{O DIREITO HUMANO À ALIMENTAÇÃO ADEQUADA (DHAA) SOB A PERSPECTIVA DOS DIREITOS HUMANOS E FUNDAMENTAIS}

A necessidade alimentar é certamente a necessidade humana prioritária no que tange ao cuidado com o corpo e à sobrevivência, sendo imperativo que tal necessidade seja suprida, como condição de um mínimo existencial exigível para o desenvolvimento da vida com dignidade, o que requer que tal necessidade seja tratada como um direito do indivíduo e um dever da sociedade e do Estado, de sorte que a pessoa humana seja tratada com dignidade.

\subsection{A fome e a questão alimentar no mundo}

A fome, ao longo da história humana, foi sempre um problema a ser enfrentado. A luta pela sobrevivência exige em primeiro lugar a satisfação das necessidades mais básicas, sendo que a necessidade de alimentação está em primeiro lugar nesta escala.

Não obstante nunca se tenha produzido tantos alimentos, em razão do avanço científico e tecnológico, o problema da fome no mundo continua a ser uma realidade.

A Organização das Nações Unidas divulgou em 2017 um relatório da situação da fome no mundo até o ano de 2016. A seguir a transcrição de parte do conteúdo do relatório:

\section{El hambre en aumento}

Tras un descenso prolongado durante más de una década, el hambre en el mundo parece estar aumentando de nuevo, afectando a un $11 \%$ de la población mundial.

El hambre en el mundo aumenta: se estima que el número de personas subalimentadas pasó de 777 millones a 815 millones en 2016

Junto con el aumento de la proporción de la población mundial que padece hambre crónica (prevalencia de la subalimentación), el número de personas subalimentadas en el mundo 
también aumentó hasta los 815 millones con respecto a los 777 millones de 2015. ${ }^{1}$

Dentre as causas do aumento da fome são apontados os conflitos armados, que tem gerado um alto número de refugiados, além da escassez de alimentos para aqueles que permanecem nas zonas de conflito, as mudanças climáticas que afetam a produção de alimentos, atingindo de forma mais drástica as regiões mais pobres e com menos recursos tecnológicos para o desenvolvimento de uma agricultura capaz de enfrentar estas mudanças na natureza, e crise econômica.

Dentre os principais dados do relatório podemos destacar os seguintes:

\section{Fome e segurança alimentar}

O número total de pessoas com fome no mundo é de 815 milhões:

Na Ásia: 520 milhões

Na África: 243 milhões

Na América Latina e no Caribe: 42 milhões

Porcentagem da população mundial vítima da fome: $11 \%$

Ásia: $11,7 \%$

África: 20\% (Na África Ocidental: 33,9\%)

América Latina e Caribe: 6,6\%

\section{Má nutrição em todas as suas formas}

Crianças menores de 5 anos que sofrem com atraso no crescimento (estatura baixa para idade): 155 milhões; Desses, os que vivem em países afetados por distintos níveis de conflitos: 122 milhões;

Crianças menores de 5 anos que estão com o peso abaixo do ideal para a estatura: 52 milhões;

Número de adultos obesos: 641 milhões $(13 \%$ do total de adultos do planeta);

${ }^{1}$ FAO - Organización de Las Naciones Unidas para la alimentación e La Agricultura.? Cuánto nos falta para alcanzar el Hambre Cero? El estado de La seguridad alimentaria y La nutrición em el mundo 2017. Acesso em 25 de abril de 2.018. Disponivel em http://www.fao.org/state-of-food-security-nutrition/es/. Acesso em 10.10.2018. 
Crianças menores de 5 anos com sobrepeso: 41 milhões;

Mulheres em idade reprodutiva afetadas por anemia: $613 \mathrm{mi}-$ lhões (cerca de $33 \%$ do total). ${ }^{2}$

\subsection{A fome e a questão alimentar no Brasil}

No caso do Brasil, como observa Patrícia Piacentini, apud Belik, "segundo o documento da ONU, o Brasil reduziu em $82,1 \%$ o número pessoas subalimentadas no período de 2002 a 2014. A queda é superior à média da América Latina, que foi de 43,1\%, apresentando ainda um total de 3,4 milhões de pessoas subalimentadas. ${ }^{3}$

Ainda, segundo Piagentini

Uma parte das pessoas que teria dificuldade de acesso aos alimentos se beneficia de programas públicos, como o programa nacional de merenda escolar, que atende 42 milhões de crianças todos os dias. Pelos dados teóricos, pode ser que essas crianças estivessem passando fome, mas na prática não estão", completa.

Para a ActionAid, o Brasil é o melhor exemplo de disposição para o enfrentamento da fome e da pobreza. "A vontade política foi fundamental, mas já havia mobilização em parte da sociedade que se recusava a aceitar a fome como um fenômeno natural, como determinados setores queriam fazer crer. E, na década de 1990, isso eclodiu com muita força com a Campanha contra a Fome", afirma Menezes.

A determinação em aplicar políticas públicas para enfrentar o problema foi o elemento que faltava para o país obter os resultados agora reconhecidos por organismos internacionais, inclusive a ONU, que indicou que o Brasil saiu do Mapa da Fome Mundial. ${ }^{4}$

2 ONUBR - Nações Unidas no Brasil. ONU - após uma década de queda, fome volta a crescer no mundo. Disponível em https://nacoesunidas.org/onu-apos-uma-decada-de-queda-fome-volta-a-crescer-no-mundo/. Acesso em 25 de abril de 2018.

${ }^{3}$ PIACENTINI, Patrícia. A fome no mundo. Apesar do avanço na produção de alimentos, 795 milhões de pessoas ainda passam fome segundo a ONU. In: Revista Pré-Univesp, n. 61, dez. 2016/jan. 2017. Disponível em http://pre.univesp.br/a-fome-nomundo\#.WuDD9n9G2Uk. Acesso em 25 de abril de 2018.

${ }^{4}$ PIACENTINI, Patrícia. Op. cit. 
Assim, não obstante avanços significativos nas duas últimas décadas no Brasil, o fato é que ainda temos um significativo déficit de pessoas em condição de subalimentação, enquanto o problema é gravíssimo em muitas outras áreas do mundo, e exige uma ação por parte dos estados constituídos e dos organismos internacionais no sentido de combater a fome e possibilitar uma adequada alimentação às pessoas.

\subsection{O direito humano à alimentação adequada}

O Direito Humano à Alimentação Adequada, conforme apontado por Conti e Piovesan (2007) é um direito assegurado a todo o ser humano na condição de sua própria existência, sendo considerados direitos inalienáveis e independentes de qualquer legislação específica em âmbito nacional, estadual, municipal ou distrital, estando associado ao princípio da dignidade da pessoa humana e aos próprios Direitos Humanos, a partir da organização da humanidade no planeta Terra.

Considerando a história da humanidade, são diversas as transformações sofridas pela sociedade, pela política, pela economia, dentre outras áreas, que de uma ou outra forma afetam e impactam as atividades e vidas humanas. É primordial compreender o percorrer da história para entender a necessidade de estabelecimento dos direitos humanos. Apesar de se tratarem de direitos que supostamente deveriam ser naturais ao homem, o determinar de proteção aos direitos humanos foi incorporado e desenvolvido com o passar do tempo, resultado de conflitos e estudos teóricos, fortalecidos pela resistência a práticas abusivas regulares. Bobbio reconhece:

Os direitos do homem, por mais fundamentais que sejam, são direitos históricos, ou seja, nascidos em certas circunstâncias, caracterizados por lutas em defesa de novas liberdades contra velhos poderes, e nascidos de modo gradual, não todos de uma vez e nem de uma vez por todas (BOBBIO, 1992, p.5)

O próprio termo 'direitos humanos' já foi e ainda é alvo de discussões fomentadas pela falsa sensação de obviedade acerca de seu significado 
literal. Estas falsas deduções, porém, podem ser culpadas por obstaculizar a compreensão acerca do real objetivo da garantia destes direitos. Pode-se compreender que direitos humanos sejam aqueles indiscriminadamente oferecidos ao ser humano pelo simples fato de fazer parte da espécie. Em tese os preceitos são estes, contudo há de se considerar as diversas particularidades existentes nas relações humanas, responsáveis pela exclusão e afastamento de diversos indivíduos por conta de socialização, divergências políticas, contextos históricos, entre outros (CHAUÍ, 1989).

Não é correto afirmar que a sociedade nasceu já possuidora/detentora destes ditos direitos humanos, muito pelo contrário: a percepção de necessidade de consolidação manifestou-se em consonância com a decorrência de alguns acontecimentos marcantes na história da humanidade, como revoluções, situações econômicas, aspectos políticos e demais outros agentes de perturbação em grandes níveis (ANTUNES, 2005). E, ainda que os direitos fossem claros desde o princípio, é evidente a indispensabilidade de um cuidado maior relativo a estas questões; não fosse indispensável as reivindicações sequer teriam motivos para serem requeridas primeiramente.

Os direitos fundamentais, por sua vez, surgem como consequência da sequência de aprovação dos direitos humanos, legisladores daqueles direitos julgados como naturalmente pertencentes ao ser humano. Canotilho (1998) esclarece os conceitos:

As expressões direitos do homem e direitos fundamentais são frequentemente utilizadas como sinônimas. Segundo a sua origem e significado poderíamos distingui-las da seguinte maneira: direitos do homem são direitos válidos para todos os povos e em todos os tempos; direitos fundamentais são os direitos do homem, jurídico-institucionalmente garantidos e limitados espaço-temporalmente. Os direitos do homem arrancariam da própria natureza humana e daí o seu caráter inviolável, intertemporal e universal; os direitos fundamentais seriam os direitos objetivamente vigentes numa ordem jurídica concreta (CANOTILHO, 1998, p. 259).

Conti e Piovesan (2007) apontam que o Direito Humano à Alimentação 
Adequada (DHAA) é contemplado em uma perspectiva que envolve tanto os Direitos Humanos quanto os Direitos Fundamentais e Sociais em um contexto verdadeiramente aplicável. Os autores apontam que os Direitos Humanos devem abranger todos os pressupostos básicos para que os homens vivam dignamente, como o acesso à saúde, educação, moradia e o próprio direito à alimentação, os quais são contemplados de modo universal, inalienável, interdependentes e inter-relacionados.

Gamba e Montal (2010), no mesmo sentido, apontam que o direito humano à alimentação não é concebido tão somente como uma responsabilidade local, sendo considerado uma responsabilidade global, justamente por tratar de um direito humano. Assim, devem ser empregados esforços em âmbito internacional para que se cumpram os preceitos fundamentais que asseguram que todos os indivíduos possam ter acesso à uma alimentação adequada e de qualidade.

Piovesan (2007), no mesmo sentido, contempla que a proteção dos direitos humanos não deve ser dependente do domínio estatal, uma vez que os mesmos são concebidos como interesses, necessidades e responsabilidades internacionais. A proteção de direitos como o Direito à Alimentação Adequada, de tal forma, advém de tratados internacionais que versam sobre a consciência ética contemporânea compartilhada pelos Estados, invocando um consenso internacional acerca doe temas centrais aos direitos humanos, buscando salvaguardá-los.

Conforme apontado anteriormente, os direitos humanos são conquistas históricas da humanidade. O Direito à Alimentação Adequada, no mesmo sentido, é enquadrado como um componente dos direitos humanos, no sentido que:

As necessidades humanas relacionadas à alimentação e à nutrição começaram a ser percebidas como direito do ser humano dentro do direito humanitário (Convenção de Genebra de 1864), quando se identificou o poder sobre o alimento como forma de dominação de um ser humano sobre outro, de um Estado sobre outro, enfim, como arma de guerra. O direito humanitário tem suas raízes na "consciência do mundo", também chamada "consciência pública" ou, mais especificamente, “consciência de identidade" (GAMBA; MONTAL, 2010, p. 66). 
Siqueira (2011) também ressalta que o acesso a alimentos adequados, não padecer de fome e desnutrição é um direito humano, sendo considerado direito prioritário pela Organização das Nações Unidas (ONU). A ausência de uma boa alimentação, composta pelas calorias mínimas necessárias para a manutenção da vida humana pode ser desencadeada por inúmeros fatores, sobretudo devido às questões econômicas e ao fornecimento de alimentos contaminados nos países mais pobres. O Direito à Alimentação Adequada, assim, é indispensável para a sobrevivência, crescimento físico, desenvolvimento mental, desempenho, produtividade, saúde e bem-estar.

Nesse sentido:

Como desdobramento da forma de tratamento primordial dada à preservação da vida e da dignidade humana pela Constituição Federal de 1988 pode-se afirmar a necessária tutela da saúde e, desta, é que se pode afirmar a existência de um direito fundamental à alimentação, seja de forma explícita como muitas vezes aparece no ordenamento jurídico brasileiro ou implícito nos textos legais pátrios (SIQUEIRA, 2011, p. 52).

O direito fundamental/humano a uma alimentação adequada é reconhecido em diversos instrumentos internacionais a partir de sua previsão original do artigo 25 da Declaração Universal dos Direitos Humanos, onde é avaliado a partir do fomento ao direito a um padrão de vida, sendo reafirmado pelo artigo 11 do Pacto Internacional de Direitos Econômicos, Sociais e Culturais (CARVALHO, 2012).

Em sua segunda dimensão, o direito fundamental à alimentação constitui-se como um direito social, de modo que:

O direito fundamental à alimentação constitui um direito de segunda dimensão, denominado de direito social. A nota distintiva deste direito é a sua dimensão positiva, uma vez que se cuida não mais de evitar a intervenção do Estado na esfera da liberdade individual, mas, sim, de propiciar um direito de participar do bem-estar social. O que caracteriza este direito é a sua dimensão positiva, dado que objetiva não mais obstar 
as ingerências do Estado no âmbito das liberdades individuais, mas exigir do Estado a sua intervenção para atender as crescentes necessidades do indivíduo. São direitos de crédito porque, por meio deles, o ser humano, passa a ser credor das prestações sociais estatais (CARVALHO, 2012, p. 182).

Esse é um dos elementos fundamentais sob o qual é concebido o presente estudo, uma vez que, ainda que o Direito à Alimentação Adequada independa de legislações nacionais, municipais, distritais e estaduais, é dever do Estado promover ações para objetivar o alcance de tal direito humano, fundamental e social.

Dentro desse contexto, Gamba e Montal (2010) apontam que o reconhecimento dos direitos fundamentais sociais não se dá tão somente nos documentos internacionais, mas também nas numerosas constituições, de modo que as garantias envolvendo esses direitos não se esgotam no plano interno estatal, diante da existência do Pacto Internacional de Direitos Econômicos, Sociais e Culturais (PIDESC) e seu órgão de monitoramento (Comitê de Direitos Econômicos, Sociais e Culturais das Nações Unidas - CDESC), o qual afirma que o direito a uma alimentação adequada está indissociavelmente vinculado à dignidade da pessoa humana e da própria justiça social, dado que requer a adoção de políticas econômicas, ambientais e sociais adequadas nos planos nacional e internacional, direcionadas para a erradicação da pobreza e o alcance de todos os direitos humanos aplicáveis a todos os indivíduos.

De acordo com Carvalho (2012), não basta simplesmente que o indivíduo tenha acesso ao alimento para que tal direito seja efetivado, uma vez que a formulação do direito fundamental é concebida de maneira inseparável ao direito humano à nutrição, de modo que o alimento só atinge aos objetivos para a efetivação de tal direito quando o ser humano se encontra nutrido, saudável, digno e cidadão. Por isso, o direito à alimentação é condicionado aos direitos fundamentais sociais e humanos, ou seja, concebido tal direito como o "Direito à Alimentação Adequada.

Assim:

O Estado tem um vasto campo em que deve atuar para a concretização do direito a alimentação adequada das pessoas 
com deficiência. Seja realizando campanhas de conscientização e instrução, seja fiscalizando o cumprimento das normas, aqui se destacando entre outras as de direito do consumidor, bem como, se necessário, no fornecimento de alimentos especiais, o que importa é que o Estado não pode ser omisso nesses casos, mas sim deve envidar esforços para facilitar o acesso dessas pessoas à alimentação necessária e da forma adequada, com o fim precípuo de garantir a elas uma existência digna. O texto constitucional de 1988 cuidou de trazer expressamente a previsão quanto ao direito fundamental à alimentação, e o fez no artigo $6^{\circ}$ daquele diploma (SIQUEIRA, 2011, p. 53).

A partir de tal contextualização, torna-se possível aprofundar a Segurança Alimentar nas relações de consumo, sob a perspectiva do entendimento do Direito à Alimentação Adequada como um direito humano e fundamental social.

\section{A SEGURANÇA ALIMENTAR: CONCEITO E CONTEXTUALIZAÇÃO NAS RELAÇÕES DE CONSUMO}

A Segurança Alimentar pode ser caracterizada pela garantia de todos ao acesso de alimentos de qualidade, em quantidade suficiente e de modo permanente, com base em práticas saudáveis e sem comprometer o acesso a outras necessidades essenciais e nem comprometer o sistema alimentar futuro (BERALDO, 2009).A concepção de segurança alimentar está intimamente relacionada à construção do bem-estar social e equidade em relação ao acesso ao alimento. O conceito, de tal forma, está relacionado ao próprio conceito de sustentabilidade, que diz respeito às satisfações da geração presente sem comprometer as necessidades de gerações futuras.

Para Manglia (2009) a segurança alimentar era compreendida como uma política consistente na armazenagem estratégica, segura e adequada de alimentos, e não como um direito de todo o ser humano a ter acesso a uma alimentação saudável, de modo que seu foco tradicional estava no alimento e não no ser humano propriamente dito. Entretanto, a autora ressalta que o con- 
ceito passou a ganhar um novo corpo a partir de 1983, quando a Organização de Alimentos e Agricultura das Nações Unidas (FAO) apresentou um conceito de segurança alimentar baseado em três objetivos: (1) oferta adequada de alimentos; (2) estabilidade da oferta e dos mercados de alimentos; (3) segurança no acesso aos alimentos ofertados.

A autora supramencionada destaca ainda que a sustentabilidade passou a ser incorporada no conceito da segurança alimentar a partir da década de 1990, em meio às constantes discussões acerca do meio ambiente, englobando em seu conceito as noções de alimento seguro, qualidade do alimento, balanceamento da dieta, informações sobre os alimentos e opções de hábitos alimentares em modos de vida. O conceito de segurança alimentar, assim, passou a ser inserido no contexto do direito à vida, à dignidade, à autodeterminação e à satisfação de outras necessidades básicas, sendo estimulada a partir da assistência ao uso adequado de água, saneamento, saúde pública, aleitamento e cuidado no preparo dos alimentos.

É neste sentido que nos remete o último relatório das Nações Unidas sofre a segurança alimentar no mundo.

La seguridad alimentaria es solo un factor determinante de los resultados nutricionales, especialmente en lo referente a los niños. Hay otros factores que influyen a este respecto. Entre ellos, cabe citar los siguientes: el nivel de educación de las mujeres; los recursos asignados a las políticas y programas nacionales de nutrición de madres, lactantes y niños pequeños; el acceso a agua limpia, saneamiento básico y servicios de salud de calidad; el modo de vida; el entorno alimentario; y la cultura ${ }^{5}$.

Santos (2011) aponta que a regulamentação da segurança alimentar em âmbito nacional é promovida pelo Código de Defesa do Consumidor (CDC), legislação que visa a organização do mercado, preservação e fiscalização das relações consumeristas, além da organização de órgãos e entidades que tratam 
do monitoramento das exigências para a segurança alimentar e segurança dos direitos do consumidor de alimentos, como o Ministério da Saúde, a Anvisa e o Ministério da Agricultura.

O parágrafo $6^{\circ}$ do artigo 18 do Código de Defesa do Consumidor (Lei $\left.n^{\circ} 8.078 / 90\right)$ faz valer da segurança alimentar, considerando que:

\begin{abstract}
Art. 18. [...]
$\S 6^{\circ}$ São impróprios ao uso e consumo: I - os produtos cujos prazos de validade estejam vencidos; II - os produtos deteriorados, alterados, adulterados, avariados, falsificados, corrompidos, fraudados, nocivos à vida ou à saúde, perigosos ou, ainda, aqueles em desacordo com as normas regulamentares de fabricação, distribuição ou apresentação; III - os produtos que, por qualquer motivo, se revelem inadequados ao fim a que se destinam.
\end{abstract}

O artigo $9^{\circ}$ do referido diploma legislativo, ademais, impõe sanção aos fornecedores que tem conhecimentos acerca dos danos que podem ser provocados por um determinado produto à saúde e ainda assim disponibilizam tal produto no mercado sem a prestação de esclarecimento ao consumidor:

Art. $9^{\circ} \mathrm{O}$ fornecedor de produtos e serviços potencialmente nocivos ou perigosos à saúde ou segurança deverá informar, de maneira ostensiva e adequada, a respeito da sua nocividade ou periculosidade, sem prejuízo da adoção de outras medidas cabíveis em cada caso concreto.

De acordo com Santos (2011) é indispensável que sejam contempladas também as condições sob as quais o comerciante armazena ou expõe a venda de um produto, com embalagens que não possam ser danificadas e com o produto alimentar não sendo exposto a qualquer risco de contaminação ou deterioração. Para reforçar as medidas de segurança alimentar, assim, o fornecedor imediato de produtos in natura, tem responsabilidade direta perante o consumidor quanto à devida qualidade do produto. De tal modo, o CDC promove em âmbito nacional a formalização da segurança alimentar no âmbito legal, protegendo os indivíduos de abusos e de alimentos que possam colocar em risco sua saúde, segurança e bem-estar, atendendo aos preceitos do Direito à Alimentação 
Adequada. $\mathrm{O}$ autor, entretanto, levanta uma questão importante:

A ação em conjunto dessas atividades com a ANVISA oferece maior proteção aos consumidores que possuem informações necessárias para acautelar seus direitos e adquirem maior proximidade com os órgãos de proteção. Ocorre que, na conjuntura atual deparamos com a falta de interação entre o poder público, sociedade civil, projetos específicos voltados para a educação da comunidade e fiscalização dos gêneros alimentícios (SANTOS, 2011, p. 343).

Diante de tal constatação, é importante destacar os ensinamentos de Bobbio (1992), o qual contempla que é característica do Estado Democrático de Direito atender à vontade geral, uma vez que a vontade de todos comanda cada um, sendo necessário colocar o Estado de modo permanentemente proativo em função de toda sociedade como um todo. Dentro desse contexto, o Estado deve empregar esforços para assegurar a Segurança Alimentar e o direito fundamental social e humano à uma alimentação de qualidade. Tais ações podem ser traduzidas através das políticas públicas, conforme será apresentado no capítulo seguinte.

\section{POLÍTICAS PÚBLICAS PARA A CONCRETIZAÇÃO DA SEGURANÇA ALIMENTAR E DO DIREITO À ALIMENTAÇÃO}

A formulação e execução de políticas públicas de segurança alimentar e garantidoras do direito à alimentação é de fundamental importância para a concretização do direito fundamental a alimentos e, por consequência, dos direitos de cidadania, tendo em vista que estar bem alimentado é condição sine qua non para que o indivíduo possa se desenvolver, lutar por seus direitos, e se ver de forma efetiva como cidadão.

\subsection{Caracterização de Políticas Públicas}

Para que possa ser analisada a ação estatal para a concretização da segurança alimentar e do direito à alimentação adequada, é indispensável que se- 
jam analisadas as políticas públicas em caráter geral. Apesar de em sua sintaxe o significado ser claro, existe mais de uma compreensão acerca do significado de Políticas Públicas. Por conseguinte, é difícil apontar qual seria o significado correto. Noções de certo e errado divergem conforme autoria e de acordo com pontos de vista. Mead (1995), por exemplo, clarifica as políticas públicas como sendo aquelas implantadas pelos governos para promover ações que influenciarão diretamente no cotidiano do povo.

Já Souza (2006) aponta outro ponto de vista, onde coloca como ponto principal das políticas públicas a necessidade de ofertar resposta para questionamentos acerca de quem sai ganhando com elas, por qual motivo e qual diferença de fato fará para a sociedade. Esta aproximação bota em um pedestal o racionalismo acerca dos procedimentos empenhados pelas políticas públicas e por vezes sofre retaliação por parte de demais teóricos, defendendo estes que assim perde-se o âmago das políticas públicas e todas as ideias que a permeiam. A abordagem em questão foca no governo, diminuindo a importância do agente principal impactado pelo resultado das políticas públicas: o povo.

O autor supramencionado ainda discorre sobre os teóricos que explicam as políticas públicas como um solucionador de problemas que aparecem dentro da sociedade. A política pública nada mais é, então, do que uma implementação para amenizar ou findar problemas públicos. Lowi (1964) foi o responsável por denominar um dos mais famigerados conceitos de políticas públicas, considerando que a política pública faz a política. A frase em questão traz como significado que determinadas políticas públicas terão ou não apoio de maneiras diferenciadas e as deliberações acerca delas caberão a diferentes setores, conforme suas necessidades. $\mathrm{O}$ autor ainda revela que, para ele, a política pública dispõe de quatro modelos, sendo que o primeiro deles diz respeito às políticas públicas distributivas, aquelas geridas pelos governos, onde a contenção de recursos não é considerada em primórdio e os impactados por seu resultado são mais um certo grupo de indivíduos e menos um coletivo inteiro.

Ainda de acordo com o autor supramencionado, sequencialmente existem as políticas regulatórias, estas sim mais plenas aos olhos da população, regidas por grupos de interesse, políticos e processos burocráticos. Em terceiro lugar aparecem as políticas redistributivas, sendo as maiores responsáveis por 
um impacto geral em um número considerável de cidadãos. As políticas redistributivas podem significar o motivo de perdas concretas ou ganhos futuros para determinados círculos, sendo representadas pelas políticas sociais universais, o sistema previdenciário e tributário, sendo elas, por sua complexidade e proporção, as que possuem o andamento em maior nível de dificuldade. Por fim existem as políticas constitutivas, aquelas responsáveis por desempenhar processos ligados aos procedimentos. Estes quatro modelos de política reunidos estabelecem conjuntos divergentes que se posicionam de acordo ou contra e se desenvolvem dentro do sistema político de acordo com isto.

Concebe-se, então, que o Estado é um agente responsável por realizar ações para entregar ao civil aquilo que previamente foi decidido pelos poderes pertinentes. Boneti (2007) expõe sua opinião sobre as definições de políticas públicas ao elaborar que:

Entende-se por políticas públicas o resultado da dinâmica do jogo de forças que se estabelece no âmbito das relações de poder, relações essas constituídas pelos grupos econômicos e políticos, classes sociais e demais organizações da sociedade civil. Tais relações determinam um conjunto de ações atribuídas à instituição estatal, que provocam o direcionamento (e/ou o redirecionamento) dos rumos de ações de intervenção administrativa do Estado na realidade social e/ou de investimentos (BONETI, 2007, p.74).

As políticas públicas são elaboradas para sanar as necessidades do povo e oferecer aos menos abastados condições para se tornar membro ativo da sociedade, entretanto os interesses que correm por de trás da formulação destas políticas também visam beneficiar os que possuem maior parcela de poder.

Guareschi (2004, p. 180) apresenta em sua obra outra maneira de denominar as políticas públicas, como "O conjunto de ações coletivas voltadas para a garantia dos direitos sociais, configurando um compromisso público que visa dar conta de determinada demanda, em diversas áreas. Expressa a transformação daquilo que é do âmbito privado em ações coletivas no espaço público". O autor defende que as políticas públicas tratam de transformar o que é assunto privado de cada cidadão em um aspecto de preocupação coletiva e pública, 
promovendo ações que garantirão os direitos dos indivíduos perante a sociedade geral.

Em sentido estrito, podemos compreender as políticas públicas como uma área do conhecimento que visa exclusivamente analisar a ação governamental e demandar que o governo exerça alguma ação acerca de determinada matéria pertinente a sociedade, além de propor alterações para tais ações de modo que elas possam ser mais produtivas de acordo com o clamor público. O processo de formulação de política pública é uma forma através do qual os governos traduzem seus propósitos em programas e ações, produzindo resultados ou mudanças desejadas na sociedade (SOUZA, 2003). Política Pública, assim, pode ser compreendida como tudo aquilo que o governo faz ou deixa de fazer.

\subsection{As Políticas Públicas para a Segurança Alimentar em Âmbito Nacional}

Santos et al. (2007) analisaram o Programa de Alimentação do Trabalhador (PAT) (instituído pela lei $\mathrm{n}^{\mathrm{o}}$. 6.231/76 e do DL $\mathrm{n}^{\mathrm{o}} .5 / 91$ ), priorizando o atendimento aos trabalhadores de baixa renda (que usufruem de uma renda de 5 salários mínimos ao mês). O PAT tem dentre seus objetivos melhorar as condições nutricionais e qualidade de vida dos trabalhadores, oferecendo benefícios para a Pessoa Jurídica optante pelo mesmo. Entretanto, os autores, ao analisarem tal política pública identificaram que:

O PAT em sua origem não contemplou a educação alimentar nas suas diretrizes básicas. Essa lacuna só foi preenchida recentemente. Uma cartilha sobre educação alimentar elaborada pelo Ministério do Trabalho e Emprego foi distribuída. Fruto das discussões do Grupo Temático de Educação Alimentar, constituído no âmbito da Comissão Tripartite, a cartilha tem como pano de fundo o quadro nutricional atual da população brasileira. A inserção da educação alimentar reflete uma tentativa de deslocar a alimentação do trabalhador do foco genuinamente energético para um enfoque de promoção à saúde e/ou prevenção de enfermidades (SANTOS et al., 2007, p. 1942-1943). 
De acordo com o diagnóstico promovido pelos autores supramencionados, ainda que mudanças importantes tenham sido introduzidas no programa, é indispensável que a avaliação do PAT se constitua como uma atividade básica e contínua por parte do governo buscando assegurar a Segurança Alimentar dos trabalhadores beneficiados pela política pública, permitindo uma reorientação a partir das falhas evidenciadas na formulação de tal política, sobretudo conscientizando os trabalhadores quanto às concepções envolvidas no direito à alimentação adequada.

Já Gonçalves et al. (2011) buscaram analisar as políticas públicas de segurança alimentar no Brasil a partir do Programa Restaurantes Populares, introduzido no Brasil a partir da década de 1990 através da implantação de unidades de alimentação em centros urbanos e em locais onde há a ampla circulação de indivíduos sob risco de integração alimentar, assegurando o fornecimento de alimentos de qualidade para a população de baixa renda, oferecendo refeições prontas, balanceadas no quesito nutricional, com cardápios variados constituídos de processos seguros de manuseios a preços acessíveis, agregando dignidade ao ato de se alimentar. Em sua análise, os autores evidenciaram que:

A implementação de uma política pública de segurança alimentar demanda um conjunto de programas articulado com outras ações de garantia da segurança alimentar e nutricional, como projetos e ações de inclusão social e assistência, merenda escolar e distribuição de alimentos à população carente, de forma a potencializar efetividade e eficácia dos programas. Embora a cobertura dos restaurantes populares ainda seja baixa em relação à população em situação de insegurança alimentar no país, os dados permitiram uma avaliação preliminar da efetividade da política pública (GONÇALVES et al., 2011, p. 109).

De tal modo, embora sejam evidenciados fatores que condicionam à uma necessidade de melhoria do Programa Restaurantes Populares (sobretudo devido à sua cobertura e alcance do público-alvo), tal política pública é considerada uma das principais em âmbito nacional, devendo sua implementação ser constante para que resultados mais positivos sejam alcançados. 
Diante da análise de tais políticas públicas, cumpre-se, por fim, analisar aindao DL n'. 7.272, que cria o Sistema Nacional de Segurança Nutricional (SISAN), buscando assegurar o direito humano à alimentação adequada, além de instituir a Política Nacional de Segurança Alimentar e Nutricional (PNSAN). Conforme disposto no artigo $5^{\circ}$ da referida legislação, a PNSAN deve contemplar todas as pessoas que vivem no território nacional. Abaixo, são apresentados seus principais objetivos:

Art. $4^{\circ}$. Constituem objetivos específicos da PNSAN: I identificar, analisar, divulgar e atuar sobre os fatores condicionantes da insegurança alimentar e nutricional no Brasil; II - articular programas e ações de diversos setores que respeitem, protejam, promovam e provejam o direito humano à alimentação adequada, observando as diversidades social, cultural, ambiental, étnico-racial, a equidade de gênero e a orientação sexual, bem como disponibilizar instrumentos para sua exigibilidade; III - promover sistemas sustentáveis de base agroecológica, de produção e distribuição de alimentos que respeitem a biodiversidade e fortaleçam a agricultura familiar, os povos indígenas e as comunidades tradicionais e que assegurem o consumo e o acesso à alimentação adequada e saudável, respeitada a diversidade da cultura alimentar nacional; e IV - incorporar à política de Estado o respeito à soberania alimentar e a garantia do direito humano à alimentação adequada, inclusive o acesso à água, e promovê-los no âmbito das negociações e cooperações internacionais.

De tal modo, a promoção de políticas públicas que visam a segurança alimentar e o acesso aos alimentos adequados é uma das prioridades do Estado brasileiro. Essas políticas públicas sempre devem contemplar as pessoas em situação de vulnerabilidade ou as que não encontram situações favoráveis para a obtenção dos alimentos adequados à manutenção de suas vidas. O Estado, assim, se posiciona dentro do contexto das políticas públicas em Segurança Alimentar, visando a tomada de ações concretas que traduzem o direito a uma alimentação adequada como direito fundamental social e direito humano. 


\section{CIDADANIA E SEGURANÇA ALIMENTAR NA SOCIEDADE DE CONSUMO}

Uma característica destacada de nossa sociedade é ser uma sociedade de consumo.

Como bem observa Zigmunt Bauman, enfrenta-se na sociedade líquido-moderna um embate entre o indivíduo e o cidadão. Segundo ele a "individualização" na sociedade líquido-moderna alcançou um significado diferente do sentido semântico que o termo adquiriu no início do pensamento liberal, pois a "individualização" consiste em transformar a "identidade" humana de um "dado" em uma "tarefa e encarregar os atores da responsabilidade de realizar essa tarefa e das consequências de sua realização. (BAUMAN, 2014).

Assim afirmar Bauman que a individualização "consiste no estabelecimento de uma autonomia de jure (independentemente de a autonomia de fato também ter sido estabelecida $)^{6}$.

Para Bauman esta potencialização do indivíduo traz graves consequências para a cidadania.

Se o indivíduo é o pior inimigo do cidadão, e se a individualização anuncia problemas para a cidadania e para a política fundada na cidadania, é porque os cuidados e preocupações dos indivíduos enquanto indivíduos enchem o espaço público até o topo, afirmando-se como seus únicos ocupantes legítimos e expulsando tudo mais do discurso público. O "público" é colonizado pelo "privado"; o "interesse público" é reduzido à curiosidade sobre as vidas privadas de figuras públicas e a arte da vida pública é reduzida à exposição pública das questões privadas e a confissões de sentimentos privados (quanto mais íntimos, melhor). As "questões públicas" que resistem a essa redução tornam-se quase incompreensíveis.

Não obstante a grande facilidade de interação através de inúmeros processos comunicativos, de fato, tem ocorrido um esvaziamento da participação efetiva nas questões de ordem pública, sendo que alguns instrumentos

${ }^{6}$ BAUMAN, Zigmunt. Modernidade Líquida. Rio de Janeiro: Zahar, 2014, p. 44. 
de comunicação como WhatsApp e Facebook acabam sendo instrumentos de manipulação, de difusão de fake news, de difusão de intimidades de pessoas públicas e privadas, mas pouco utilizados de forma inteligente e reflexiva para a discussão das questões relativas à vida pública, sendo em alguns momentos instrumentos de imbecilização das pessoas.

A colonização do espaço público pelo privado é constante, e os programas governamentais de reforma trabalhista e da previdência, por exemplo, não foram objeto de debate público na mídia, antes, esta foi usada tão somente como meio propagandístico, uma vez que os programas que trataram desta temática convidavam participantes que necessariamente concordavam com o proposto, sem que houvesse a possibilidade do contraditório, o que acabava em grande medida repercutindo no Facebook e WhatsApp, o mesmo ocorrendo com outras matérias afetas às questões políticas e jurídicas.

Entretanto, Bauman é categórico ao afirmar que

O indivíduo de jure não pode se tornar indivíduo de facto sem antes tornar-se cidadão. Não há indivíduos autônimos sem uma sociedade autônoma, e a autonomia da sociedade requer uma auto constituição deliberada e perpétua, algo que só pode ser uma realização compartilhada de seus membros. ${ }^{7}$

Ou seja, a construção da autonomia passa necessariamente pela participação política, pela cidadania, não podendo ser uma construção individualizada, mas exigindo o entrelaçamento de vontades e de propósitos, enfim, uma realização compartilhada.

Conclui Bauman que "indivíduos que reaprenderam capacidades esquecidas e reapropriaram ferramentas perdidas da cidadania são os únicos construtores à altura da tarefa de erigir essa ponte em particular". ${ }^{8}$

Para Bauman, numa sociedade de consumidores, "Consumir, portanto, significa investir na afiliação social de si próprio, o que , numa sociedade de

${ }^{7}$ BAUMAN, Zigmunt. Op. Cit. p. 55.

${ }^{8}$ BAUMAM, Zigmunt. Idem, Ibidem, p. 56. 
consumidores, traduz-se em "vendabilidade'".

Para Bauman, na sociedade de consumo todos são transformados em mercadoria, que devem se fazer vendáveis para que possam ser consumidores, sendo que aqueles que não conseguirem se vender e, por via de consequência, consumir, devem ser considerados "inválidos", marcados para a exclusão, e isto de forma irrevogável, sem apelação, sendo denominados de "consumidores falhos". Ou seja, todo o ônus recai sobre o consumidor.

Bauman é bastante incisivo ao afirmar que o objetivo principal do consumo numa sociedade de consumidores "não é a satisfação de necessidades, desejos e vontades, mas a comodificação ou recomodificação do consumidor: elevar a condição dos consumidores à de mercadorias vendáveis"10.

Baumam é bastante cético em relação à cidadania numa sociedade de consumidores, uma vez que sua análise leva-nos a perceber que está havendo um aprofundamento das exclusões sociais e uma valorização cada vez maior do capital, do mercado e suas regras.

No contexto de uma sociedade de consumo como a considerada por Bauman, em que os valores do mercado exercem um papel dominante, mister se faz que o Estado atue no sentido de realizar políticas públicas com vistas a assegurar as condições necessárias para uma vida digna, mormente no que se refere à alimentação, para que as pessoas experimentem minimamente a condição de cidadãos.

A atuação do Estado no que tange à segurança alimentar, no sentido de viabilizar as condições alimentares dignas a todos os membros da sociedade é condição indispensável de concreção da cidadania.

Em boa hora o legislador constituinte fez constar dos direitos sociais fundamentais o direito à alimentação através da Emenda Constitucional 64 de 4 de fevereiro de 2010.

O direito à alimentação é o mais básico de todos os direitos sociais, essencial para garantir a sobrevivência, vida, saúde e demais direitos dele decorrentes.

9 BAUMAN, Zigmunt. Vida para Consumo. Rio de Janeiro: Zahar, 2007, p. 75.

${ }^{10}$ BAUMAN, Zigmunt. Vida para Consumo. Op. Cit. p. 76. 
Vê-se que, numa sociedade de consumo, na qual o lucro é o valor exponencial, o direito a uma alimentação saudável e contínua é totalmente necessária, sob pena de se estabelecer processos de exclusão e desumanização.

Não há cidadania que não pressuponha a satisfação desta necessidade básica do ser humano: alimentação.

\section{CONSIDERAÇÕES FINAIS}

O presente estudo realizou uma ampla abordagem acerca da Segurança Alimentar e do Direito Humano à Alimentação Adequada (DHAA), sob a perspectiva de consolidação de tais direitos enquanto direito fundamental social e direito humano. Mesmo diante da realização de uma série de avanços, programas e mudanças em âmbito internacional, a fome continua sendo um grave problema enfrentado pela humanidade, no mesmo sentido que determinados pontos envolvendo a insegurança alimentar e o oferecimento de alimentos impróprios e inadequados ao consumo humano (como aqueles que podem ter sido expostos ao risco de contaminação, por exemplo) constituem-se como um desafio para a efetivação do DHAA.

Ainda que a Segurança Alimentar e o DHAA se caracterizem como preocupações de responsabilidade internacional e independam de legislações municipais, estaduais e nacionais, as políticas públicas se traduzem em ações concretas com o intuito de assegurar tais direitos, sobretudo diante das pessoas que se encontram em estado de vulnerabilidade ou que não contam com recursos suficientes para a obtenção de alimentos nutritivos tão necessários para a manutenção de sua saúde e sobrevivência. As políticas públicas voltadas para a concreção dos direitos humanos e fundamentais a alimentos são contempladas como as ações realizadas pelo Estado com o intuito de assegurar tais direitos fundamentais sociais e humanos.

Um dos principais pontos analisados no presente estudo deu-se na análise da Segurança Alimentar sob a perspectiva das relações de consumo. $\mathrm{O}$ Código de Defesa do Consumidor (CDC) determina quais são os alimentos impróprios para o consumo, bem como impõe sanção ao fornecedor que, sabendo que o alimento ofertado no mercado promove a insegurança alimentar. Órgãos 
como a ANVISA, o Ministério da Saúde e o Ministério da Agricultura realizam o trabalho de fiscalização e monitoramento do cumprimento dos preceitos estabelecidos para a Segurança Alimentar.

Dentre as políticas públicas analisadas, deu-se destaque ao Programa Restaurantes Populares, que possibilita em áreas estratégicas um cardápio nutritivo a um preço baixo. Essa política permite que pessoas em condição de vulnerabilidade, como por exemplo os desabrigados, possam ter acesso à uma alimentação adequada. Embora o programa tenha muito a evoluir, os resultados alcançados pelo mesmo são relativamente satisfatórios.

É indispensável que sejam implantadas novas políticas públicas e que sejam implementadas as políticas públicas já existentes para que seja assegurado o Direito Humano à Alimentação Adequada e à Segurança Alimentar para todos os indivíduos que vivem no território brasileiro. Essa é uma das perspectivas globais para que tais direitos humanos, fundamentais e sociais sejam devidamente cumpridos e assegurados pelas autoridades estatais.

\section{REFERÊNCIAS}

ANTUNES, R.B. Direitos Fundamentais e Direitos Humanos: a questão relacional. Rev. Esc. Direito, Pelotas, v. 6, n. 1, 2005.

BAUMAN, Zigmunt. Modernidade Líquida. Rio de Janeiro: Zahar, 2014.

BAUMAN, Zigmunt. Vida para Consumo. Rio de Janeiro: Zahar, 2007

BERALDO, N.A.S. Agricultores quilombolas, mediadores sociais e segurança alimentar: uma análise a partir das condições e estratégias de acesso aos alimentos da comunidade Moçambique/RS. Dissertação (Mestrado). Porto Alegre: Programa de Pós-graduação em Desenvolvimento Rural - UFRGS, 2009.

BOBBIO, Norberto. A Era dos Direitos. 1 ed. 12. tir. Rio de Janeiro: Campus, 1992.

BONETTI, L. W. Políticas públicas por dentro. Ijuí: Unijuí, 2007. 
CANOTILHO, José Joaquim Gomes. Direito Constitucional e Teoria da Constituição. 3 ed. Coimbra: Almedina, 1998.

CARVALHO, Osvaldo Ferreira. $\mathbf{O}$ direito fundamental à alimentação e sua proteção jurídico-internacional. Revista De Direito Público, Londrina, v. 7, n. 2, p. 181224, maio/ago. 2012. Disponível em . http://www.uel.br/revistas/uel/index.php/ direitopub/article/viewFile/11174/11280. Acesso em 10.10.2018.

CHAUÍ, M. Direitos humanos e medo. In: FESTER, A.C.R. (Org.). Direitos humanos e medo. 1 ed. São Paulo: Brasiliense, 1989.

CONTI, Irio Luiz.; PIOVESAN, Flávia. (Coord.) Direito Humano à alimentação adequada. Rio de Janeiro: Editora Lúmen Juris, 2007.

FAO - Organización de Las Naciones Unidas para la alimentación e La Agricultura.? Cuánto nos falta para alcanzar el Hambre Cero? El estado de La seguridad alimentaria y La nutrición em el mundo 2017. Acesso em 25 de abril de 2.018. Disponível em http://www.fao.org/state-of-food-security-nutrition/es/. Acesso em 10.10.2018.

FERREIRA FILHO, Manoel Gonçalves. Direitos humanos fundamentais. 7. ed. São Paulo: Saraiva, 2005.

GAMBA, Juliana Caravieri Martins, MONTAL, Zélia Maria Cardoso. O direito humano à alimentação adequada: revisitando o pensamento de Josué de Castro. Revista Jurídica da Presidência, Brasília, v. 11, n. 95, out. 2009/jan. 2010. Disponível em https://revistajuridica.presidencia.gov.br/index.php/saj/article/view/226. Acesso em 20.01.2018.

GONÇALVES, Maetê Pedroso; CAMPOS, Silvana Terezinha de, SARTI, Flávia Mori. Políticas públicas de segurança alimentar no Brasil: Uma análise do Programa de Restaurantes Populares. Revista Gestão \& Políticas Públicas, v. 1, n. 1, p. 92-111, 2011. Disponível em http://www.revistas.usp.br/rgpp/article/view/97826. Acesso em 15.01.2018.

GUARESCHI, Neuza et. al. Problematizando as práticas psicológicas no modo de entender a violência. In: STREY, Marlene Neves, AZAMBUJA, Mariana Porto Ruwer e JAEGER, Fernanda Pires. (Orgs.). Violência, gênero e políticas públicas. Coleção Gênero e Contemporaneidade, 2. Porto Alegre: EDIPUCRS, 2004. Disponível em https://books.google.com.br/books?id=VSEPqowQz0QC\&printsec=frontcover\&hl=pt-BR\&source $=$ gbs_ge_summary_r\&cad $=0 \# \mathrm{v}=$ onepage $\& \mathrm{q} \& \mathrm{f}=$ false. Acesso em 18.01.2018.

LOWI, Theodore J. American Business, Public Policy, Case Studies and Political Theory. World Politics, v. 16, 1964. 
MANIGLIA, E. As interfaces do direito agrário e dos direitos humanos e a segurança alimentar. São Paulo: Editora UNESP/Cultura Acadêmica, 2009.

MEAD, L. M. Public Policy: Vision, Potential, Limits. Policy Currents, fev. 1995.

ONUBR - Nações Unidas no Brasil. ONU - após uma década de queda, fome volta a crescer no mundo. Disponível em https://nacoesunidas.org/onu-apos-uma-decada-de-queda-fome-volta-a-crescer-no-mundo/. Acesso em 25 de abril de 2018.

PIACENTINI, Patrícia. A fome no mundo. Apesar do avanço na produção de alimentos, 795 milhões de pessoas ainda passam fome segundo a ONU. In: Revista Pré-Univesp, n. 61, dez. 2016/jan. 2017. Disponível em http:// pre.univesp.br/a-fome-no-mundo\#.WuDD9n9G2Uk. Acesso em 25 de abril de 2018.

PIOVESAN, F. Direitos Humanos e o Direito Constitucional Internacional. 8. ed. rev. ampl. atual. São Paulo: Saraiva, 2007.

SANTOS, C. M. B. Segurança Alimentar e Rotulagem de Alimentos sob a perspectiva do Código de Defesa do Consumidor Brasileiro. Percurso Acadêmico, Belo Horizonte, v. 1, n. 1, p. 327-346, jul./dez. 2011.

SANTOS, Leonor Maria Pacheco et al. Avaliação de políticas públicas de segurança alimentar e combate à fome no período 1995-2002. 2 - Programa de Alimentação do Trabalhador. Caderno Saúde Pública, Rio de Janeiro, v. 23, n. 8, p. 1931-1945, ago. 2007. Disponível em http://www.scielo.br/scielo.php?script=sci_arttext\&pid=S0102-311X2007001100016. Acesso em 15 de fevereiro de 2.018.

SIQUEIRA, Dirceu Pereira. P. O Direito Fundamental à alimentação adequada e suas consequências na ordem jurídica brasileira: uma interpretação sob o viés da efetividade. Revista Argumenta, Jacarezinho, UENP, n. 14, p. 41-57, 2011.

SOUZA, Celina. Política Públicas: uma revisão da literatura. Sociologias, Porto Alegre, Ano 8, n. 6, jul/dez 2006. Disponível em http://www.scielo.br/pdf/soc/n16/ a03n16. Acesso em 20 de fevereiro de 2018.

Políticas públicas: questões temáticas e de pesquisa. Caderno $\mathrm{CRH}$, Salvador, n. 39, jul./dez. 2003. Disponível em https:/ / edisciplinas.usp.br/pluginfile.php/359019/mod_resource/content/1/T2\%20Celina\%20Souza\%20Politicas\%20 publicas\%20RCRH-2006-273.pdf. Aceso em 25.02.2018. 